\title{
Atividade lúdica e educativa para higienização das mãos em tempos de pandemia: relato de experiência
}

RESUMO | Objetivo: descrever a experiência de uma atividade lúdica para reflexão da técnica de higienização das mãos entre profissionais de enfermagem frente ao atendimento de paciente com Coronavírus. Método: trata-se do estudo de um relato de experiência profissional sobre uma atividade educativa realizada com 25 profissionais que estão na linha de frente do COVID-19. Resultado: os participantes perceberam as falhas durante o procedimento de higienização das mãos e foram esclarecidos sobres as principais dúvidas sobre a técnica correta, tempo de fricção, quantidade de sabão a ser utilizado, fazendo com que suas práticas fossem postas à prova. Conclusão: a educação permanente é primordial para incentivar e realizar as técnicas adequadas, principalmente as que se referem às barreiras de exposição ao vírus. O aumento da qualidade na higienização das mãos, exige investimento na educação continuada para os profissionais de saúde e mudanças dos aspectos relacionados às crenças e à cultura desses profissionais.

Palavras-chaves: Profissionais de enfermagem; Lavagem das mãos; Pandemias; Infecções por coronavirus.

\begin{abstract}
Objective: to describe the experience of a playful activity to reflect on the hand hygiene technique among nursing professionals regarding the care of patients with Coronavirus. Method: this is a study of a professional experience report about an educational activity carried out with 25 professionals who are on the front line of COVID-19. Result: the participants realized the flaws during the hand hygiene procedure and were clarified about the main doubts about the correct technique, friction time, amount of soap to be used, causing their practices to be put to the test. Conclusion: the permanent education is essential to encourage and carry out appropriate techniques, mainly those related to the barriers of exposure to the virus. The increasing in quality of hand hygiene requires investment in continuing education for health professionals and changes in the aspects related to the beliefs and culture of these professionals.
\end{abstract}

Keywords: Nursing professionals; Handwashing; Pandemics; Coronavirus infections.

RESUMEN | Objetivo: describir la experiencia de una actividad lúdica para reflexión sobre la técnica de higienización de las manos entre profesionales de enfermería en relación al cuidado de pacientes con Coronavirus. Método: se trata de un estudio de un informe de experiencia profesional sobre una actividad educativa realizada con 25 profesionales que se encuentran en la primera línea del COVID-19. Resultado: Ios participantes se notaron las fallas durante el procedimiento de higienización de las manos y se aclararon las principales dudas sobre la técnica correcta, tiempo de fricción, cantidad de jabón a utilizar, haciendo con que sus prácticas sean puestas a prueba. Conclusión: la educación permanente es fundamental para incentivar y realizar las técnicas adecuadas, principalmente aquellos que se refieren a barreras de exposición al virus. El incremento de la calidad de la higienización de las manos requiere inversiones en educación continua para los profesionales de la salud y cambios en los aspectos relacionados con las creencias y la cultura de estos profesionales.

Palabras claves: Profesionales de enfermería; Lavarse las manos; Pandemias; Infecciones por coronavirus.

\section{Fabiano Fernandes de Oliveira}

Enfermeiro graduado pelo Centro Universitário Teresa D'Ávila - UNIFATEA - Lorena - São Paulo. Docente no Curso de Graduação e Enfermagem da Escola Superior de Cruzeiro - ESC - Cruzeiro - São Paulo e no Curso de Enfermagem do Centro Paula Souza - São Paulo. Mestre em Enfermagem pelo Programa Pós-Graduação, Curso de Mestrado Acadêmico, da Universidade Estadual Paulista -UNESP- Botucatu, São Paulo- Brasil. ORCID: 0000-0001-6768-4257

\section{Adaiza Kelly Honorato}

Enfermeira graduada pela Escola Superior de Cruzeiro. Cruzeiro -ESC, Cruzeiro - São Paulo - Brasil.

ORCID: 0000-0002-1844-5070

Recebido em: 30/11/2020

Aprovado em: 02/02/2021

\section{INTRODUÇÃO}

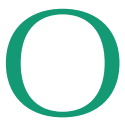
SARS-CoV-2 é um vírus identificado como a causa de um surto de doença respiratória, detectado pela primeira vez em Wuhan - China - em dezembro de 2019. Muitos pacientes acometidos por esse vírus tinham algum vínculo com o comércio de frutos do mar e animais, o que sugeriu a transmissão da doença de animais para pessoas. No entanto, um número crescente de pacientes supostamente não teve exposição ao mercado de animais, indicando a ocorrência de disseminação de pessoa para pessoa. ${ }^{(1)}$

Atualmente, já está bem definido que esse vírus possui uma alta e sustentada transmissibilidade entre os seres humanos. Ainda não existe vacina disponível para toda a população a fim de prevenir a infecção pelo SARS-CoV-2. Assim, a melhor maneira de prevenir a doença causada por esse vírus, denominada COVID-19, é adotar ações para impedir a sua disseminação, sendo uma delas a higiene das mãos (HM.) ${ }^{(2)}$

Nessa perspectiva, a higiene das mãos é um dos hábitos mais importantes para evitar doenças e infecções. Essa medida simples é tão essencial que a Organização Mundial da Saúde (OMS) elegeu 5 de maio como o Dia Mundial de Higiene das Mãos e data de divulgação da campanha "Salve vidas: higienize suas mãos". Em 2019, a proposta pela OMS, 
apoiada pela Agência Nacional de Vigilância Sanitária (ANVISA), foi o "Cuidado seguro para todos está nas suas mãos". ${ }^{(3)}$

Assim, o objetivo dessas campanhas e mobilizações é colocar o tema no centro das atenções em todo o mundo e estimular os profissionais a desempenhar boas práticas de cuidados limpos e seguros para a prevenção de infecções em pacientes nos serviços de saúde. ${ }^{(4)}$

Sabe-se que a higiene das mãos (com preparação alcoólica a $70 \%$ ou com sabonete líquido) é uma das ações para minimizar a propagação de patógenos (organismos capazes de causar doenças), incluindo o novo coronavírus. ${ }^{(5)}$

Nesse sentido, ressalta-se que a HM das mãos é uma das principais precauções relacionadas à segurança do paciente e à qualidade da assistência de enfermagem. Destacam-se, nesse cenário, a redução das Infecções relacionadas à Assistência à Saúde (IRAS) para a menor taxa de incidência admissível e o baixo risco ou dano dispensável associados à atenção à saúde. ${ }^{(6)}$

Em virtude dessas constatações, a Organização Pan-Americana da Saúde (OPAS) sugere que a HM seja empregada por qualquer estabelecimento de saúde, independente dos recursos disponíveis. Para isso, propõem-se os cinco momentos para HM: (I) antes de contato com paciente; (II) antes da realização de procedimento asséptico (como inserção de cateteres ou administração de medicamentos endovenosos); (III) após risco de exposição a fluídos corporais (como sangue, saliva ou suor); (IV) após contato com paciente e/ou (V) após contato com as áreas próximas ao paciente (mobiliário, maçanetas, bombas de infusão contínua ou qualquer superfície nas adjacências do paciente). ${ }^{(7)}$

Neste cenário, o estudo justifica-se por ser um tema estratégico dentro das organizações de saúde e assumir o compromisso de sensibilizar e promover a conscientização para a seriedade da higienização das mãos corretamente por todos os profissionais envolvidos no cuidado com a saúde, desde colaboradores administrativos aos que prestam assistência direta ao paciente, enaltecendo a função do enfermeiro como educador permanente, primordialmente na ocasião da pandemia.

Além disso, a pesquisa traz à tona a discussão quanto à possibilidade de amortizar a disseminação do Covid-19 e agravos à saúde dos pacientes e da equipe que se encontrar no enfrentamento à pandemia.

Pelo exposto, a presente pesquisa
Sabe-se que a higiene das mãos (com preparação alcoólica a $70 \%$ ou com sabonete líquido) é uma das ações para minimizar a propagação de patógenos lorganismos capazes de causar doenças), incluindo o novo coronavírus. teve como objetivo descrever a experiência de uma atividade lúdica para reflexão da técnica de higienização das mãos entre profissionais de enfermagem frente ao atendimento de paciente com Coronavírus.

\section{MÉTODO}

Trata-se de um estudo descritivo, reflexivo, de natureza qualitativo, do tipo relato de experiência, sobre o conhecimento vivenciado a partir de uma atividade de educação permanente. Tal atividade foi realizada para profissionais de enfermagem que estão na linha de frente do atendimento prestado a paciente confirmado ou com suspeita de COVID-19.

O cenário do estudo foi um serviço de pronto atendimento de uma instituição hospitalar de médio porte, situado à região do Vale do Paraíba, no interior do estado de São Paulo - Brasil. O local conta com um total de 156 leitos, sendo 56 desses, destinados ao setor de atendimento a vítimas da pandemia por Coronavírus. O hospital oferece atendimento particular de convênios médicos e do Sistema Único de Saúde (SUS). Esse serviço é referência para tratamento de COVID-19 na região adjacente.

Quanto à questão temporal, delimita-se a experiência profissional vivenciada nos meses de março a junho do ano de 2020, com atividades lúdicas as quais tinham durabilidade entre 40 a 50 minutos.

Realizou-se uma ação de educação permanente em forma de oficina prática, 
com 25 colaboradores que atuam no setor de atendimento ao COVID-19, sendo: 10 técnicos de enfermagem; 5 enfermeiros; 5 recepcionistas; e 5 profissionais do serviço de zeladoria. Desse total, 4 são do sexo masculino e 21 feminino, com idade entre 23 a 45 anos. Todos atuavam nesse setor desde abril de 2020 .

O relato foi baseado na experiência de enfermeiros com conhecimento sobre a assistência frente à pandemia de CO-
VID-19, bem como suas práticas associadas à realização de educação permanente em saúde.

Os dados aqui relatados demonstram a vivência que emergiu dos relatos e das observações feitas durante a concretização de ações lúdicas de educação em saúde, com estudos e discussões entre as profissionais de enfermagem na estrutura interna da instituição onde foram desenvolvidas as atividades.

\section{Figura 1: Caixa de Fibra de Densidade Média (MDF) e substituição do sabonete líquido pela tinta guache neon nas mãos dos colaboradores, São Paulo, Brasil, 2020.}
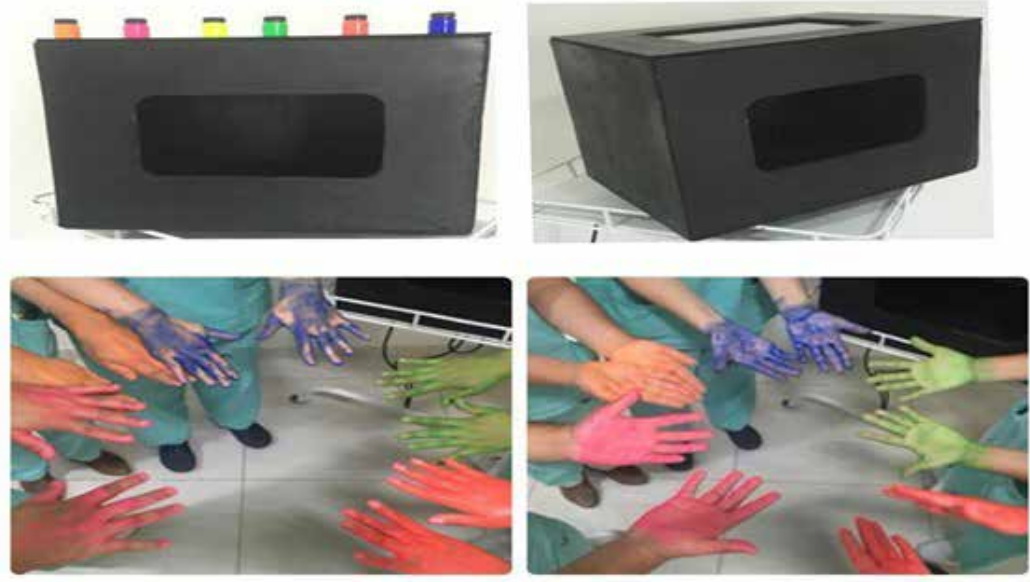

Fonte: Arquivo dos autores, 2020

\section{Figura 2: Efeito da luz após a higienização das mãos com tinta guache neon, São} Paulo, Brasil, 2020.
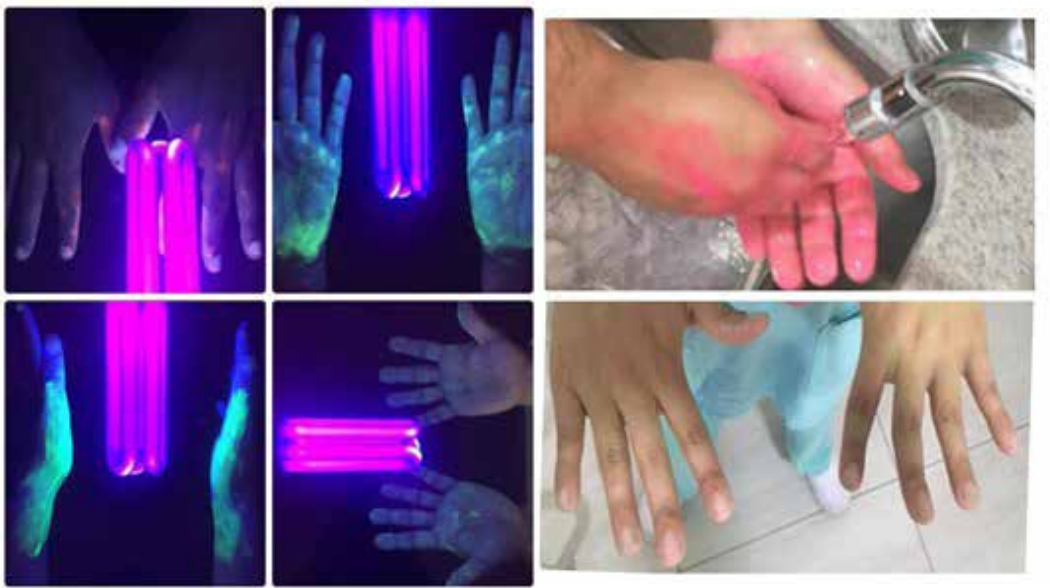

Por se tratar de um relato de experiência, não foi necessária a submissão ao Comitê de Ética em Pesquisa. Mesmo tratando-se desse tipo de estudo, todos os princípios éticos foram seguidos, conforme as recomendações nacionais e internacionais de pesquisa. Vale ressaltar, ainda, que se obteve a anuência da instituição para divulgação da experiência.

\section{RESULTADO}

Para realização da atividade, em um primeiro momento, confeccionou-se uma caixa de madeira, conhecida como painel de Fibra de Densidade Média (MDF), feita com fibras e resina sintética, por isso o resultado é um material uniforme. Nessa caixa, havia, na parte anterior, uma abertura para inserção das mãos, na porção superior um feixe para visualização interna, e, no interior, uma luz negra. O compartimento foi pintado na cor preta fosca para intensificar a luz interna.

A segunda fase, de acordo com a (Figura 1), contemplou a utilização de tinta guache neon, com a finalidade substituir o sabonete líquido, aplicado nas mãos dos participantes, os quais foram orientados a realizar a técnica de higienização das mãos com os movimentos de fricção de forma adequada. Logo após, foram observadas as regiões que não foram limpas adequadamente durante o procedimento.

$\mathrm{Na}$ terceira fase, conforme (Figura 2), os profissionais higienizaram as mãos com água corrente e, em seguida, inseriam as mãos novamente dentro da caixa lúdica. O objetivo foi levá-los a observar os resíduos da tinta guache, principalmente nas áreas do dorso superior das mãos, polegares e ao redor das cutículas, pois a tinta guache neon destaca os locais onde a fricção não foi efetiva.

Posteriormente, com a visualização de suas próprias mãos, os participantes perceberam as falhas durante a técnica de higienização e foram esclarecidos sobre as principais dúvidas frente a sequência correta para o procedimento, o tempo

Fonte: Arquivo dos autores, 2020 
médio de fricção e a quantidade de sabão líquido a ser aplicada, fazendo com que suas práticas fossem postas à prova.

Em linhas gerais, a atividade, além de evidenciar a sujidade nas mãos, promoveu interação entre a equipe, fortalecendo o trabalho conjunto e a comunicação efetiva.

Ressaltamos que, após essa etapa, foi exibido o cartaz disponível no manual da Agência Nacional Vigilância Sanitária (ANVISA), que ilustra as orientações gerais para implantação das práticas de segurança do paciente em hospitais de campanha e demais estruturas provisórias, durante a pandemia de COVID-19. ${ }^{(8)}$

O mesmo manual recomenda as seguintes etapas de desenvolvimento da técnica de higienização simples das mãos: retirar adornos; abrir a torneira e molhar as mãos, evitando encostar-se a pia; evitar água muito quente ou muito fria, a fim de prevenir o ressecamento da pele; aplicar sabão líquido na palma da mão em quantidade suficiente para cobrir todas as superfícies (seguir a quantidade recomendada pelo fabricante). Em seguida, deve-se realizar a fricção de todas as partes das mãos incluindo palmas, dorso, espaços interdigitais, dorso dos dedos, polegares, polpas digitais e punhos; depois, deve-se enxaguá-las retirando os resíduos de sabão, no sentido dos dedos para os punhos, evitando contato direto das mãos ensaboadas com a torneira. Para finalizar, o profissional deve proceder à secagem com papel toalha descartável, iniciando pelas mãos e seguindo em direção aos punhos; posteriormente, deve-se desprezar o papel tolha na lixeira destinada a resíduos comuns. A duração do procedimento depende da finalidade, no caso da HM simples é de aproximadamente 40 a 60 segundos.

\section{DISCUSSÃO}

Por conseguinte, a ausência da higienização das mãos faz parte da realidade da população brasileira. Sabe-se que já ocorreram surtos devido à não higienização das mãos dos profissionais de saúde, nas quais foram identificados vários micro-organismos. Para combater esses micro-organismos, existem diversos antissépticos e sabonetes que podem ser utilizados para a higiene das mãos durante o processo do cuidado com pacientes. ${ }^{(9)}$

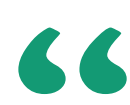

Salienta-se, também, a importância do emprego de estratégias lúdicas, para facilitar a aprendizagem entre profissionais da saúde. Essa proposta deve estar inserida em todo o processo de enfrentamento ao vírus causador da Covid-19, pois irá repercutir na qualidade do atendimento, na garantia do direito à saúde ao indivíduo e na aquisição de habilidades e confiança. Essas atividades lúdicas tendem a facilitar a fixação do conteúdo abordado, o conhecimento dos fatores desencadeantes das infecções e as formas de como evitá-los.

Assim, entendemos que o uso de estratégias lúdicas em atividades de educação permanente é primordial para mediar essa relação, corroborando em diversos benefícios tanto para o profissional quanto para paciente. ${ }^{(12)}$

Ressalta-se, igualmente, a relevância do comportamento das pessoas, o que tem sido uma questão fundamental para a prática dos profissionais envolvidos. Acerca disso, é importante lembrar a adesão às medidas preventivas de segurança durante a pandemia. Nessa perspectiva, é fundamental que haja educação permanente em saúde, para que ocorram alterações e motivação comportamental, fazendo com que se criem estratégias para elevar a adesão ao procedimento da higienização das mãos. ${ }^{(13)}$

Estudos sobre assistência qualificada apontam que a higienização das mãos é um extraordinário mecanismo para remoção de suor, sujidade, oleosidade, células mortas e microrganismos. Sabe-se que as mãos abrigam uma quantidade considerável de patógenos de baixa a alta virulência, sendo um meio comum de contaminação cruzada. Desse modo, a higienização mecânica com água e sabão é ideal para a diminuição da propagação de doenças infecciosas ${ }^{(14)}$

Nesse sentido, nossa pesquisa apre-

Com isso, a higienização das mãos tem sido preconizada como estratégia mais eficaz para redução de infecção relacionada à assistência à saúde (IRAS), em Programas de Controle de Infecção. ${ }^{(10,11)}$ senta limites por tratar-se de um relato de experiência, sendo assim, não foram analisados indicadores que pudessem mostrar resultados mesuráveis, alcançados com a estratégia lúdica empregada. 
Por outro lado, a pesquisa contribuiu para o conhecimento sobre a técnica de higienização das mãos, para prestação de cuidados diretos e indiretos aos pacientes, nos casos suspeitos ou confirmados de coronavírus, proporcionando segurança do paciente e do profissional.

Dessa forma, com as atividades propostas e realizadas, foi possível contribuir com a instituição cuidando dos seus colaboradores da equipe de enfermagem, os quais estão na linha de frente na luta e enfrentamento dessa doença pandêmica - COVID-19 - como também da população atendida por esses profissionais, de um modo geral.

\section{CONCLUSÃO}

Tendo em vista que o vírus foi recentemente descoberto e que ainda são poucas pesquisas acerca do tema, enfatiza-se a relevância da contínua modernização técnico-científica. Entende-se que
Assegurar aos profissionais de enfermagem a realização do procedimento correto de higienização das mãos... é primordial a realização de ações de educação permanente com o intuito de promover a técnica adequada para procedimentos de atendimento ao público em hospitais, principalmente as que se referem às barreiras à exposição ao vírus, assim como as adaptações dos serviços de saúde.

Assegurar aos profissionais de enfermagem a realização do procedimento correto de higienização das mãos, bem como os insumos em quantidade necessária e com qualidade reconhecida, são ações essenciais as quais permitem que os profissionais não atuem com carga microbiana de transmissão em suas mãos, além de evitar seu afastamento pela contaminação da doença.

Reafirma-se, por fim, que o aumento da qualidade na higienização das mãos exige investimento na educação permanente para os profissionais de saúde mas também mudanças nos aspectos relacionados às crenças e à cultura desses profissionais. 2

\section{Referências}

1. Sequinel R, Lenz GF, Silva FJLB, Silva FR. Alcohol based solutions for hand and surface sanitation in the prevention of COVID-19: informative compendium regarding the involved chemistry. Quim Nova. 2020;43(5):679-84. doi: http://dx.doi.org/10.21577/0100-4042.20170553

2. Oliveira SMC, Neto I, Collares CF, Oliveira MAB. Medical education: palliative medicine and hand hygiene and their role in the pandemic of Covid-19. Humanidades \& Inov. 2020;7(8):587-94.

3. Freitas BMBM, Alves MDSM, Gaíva MAM. Prevention and control measures for neonatal COVID-19 infection: a scoping review. Rev Bras Enferm. 2020;73(Suppl 2):e20200467. doi: http://dx.10.1590/0034-7167-2020-0467

4. Oliveira AC, Lucas TC, Iquiapaza RA. 0 que a pandemia da Covid-19 tem nos ensinado sobre adoção de medidas de precaução? Texto Contexto Enferm. 2020;(29):e20200106. doi: https://doi.org/10.1590/1980-265X-TCE-20200106

5. Brasil. Ministério da Saúde. Portaria n. 529, de $1^{\circ}$ de abril de 2013. Institui o Programa Nacional de Segurança do Paciente (PNSP) [Internet]. Brasília (DF); 2013 [citado em: 2015 Jul 8]. Disponível em: https://bvsms.saude.gov.br/bvs/ saudelegis/gm/2013/prt0529_01_04_2013.html

6. Cavalcante EFO, Pereira IRBO, Leite MJVF, Santos AMD, Cavalcante CAA. Implementação dos núcleos de segurança do paciente e as infecções relacionadas à assistência à saúde. Rev Gaúcha Enferm. 2019;40(esp):e20180306. doi: https://doi.org/10.1590/1983- 1447.2019.20180306.

7. Organização Pan-Americana da Saúde, Agência Nacional de Vigilância Sanitária. Manual para observadores: estratégia multimodal da OMS para a melhoria da higienização das mãos[Internet]. Brasília: OPAS e OMS; 2008 [citado em: 2020 Jul 08]. 58p. Disponível em: https://www.anvisa.gov.br/servicosaude/ controle/higienizacao_oms/manual_para_observadores-miolo.pdf

8. Brasil. Agencia Nacional de Vigilância Sanitária. Nota técnica GVIMS/
GGTES/ANVISA Nº 04/2020. Orientações para serviços de saúde: medidas de prevenção e controle que devem ser adotadas durante a assistência aos casos suspeitos ou confirmados de infecção pelo novo coronavírus (SARS-CoV-2) [Internet]. 2020;[Citado em: 2020 Jul 08]. Disponível em: https://coronavirus. saude.gov.br/

9. Soares DC, Cecagno D, Quadros LCM, Spagnolo LML, Cunha TN. Educational actions to combat COVID-19: experience report. RSD [Internet]. 2020 Jul [citado em: 2021 Jan 26 ];9(8):. Disponível em: https://rsdjournal.org/index.php/ rsd/article/view/5207

10. Gonçalves BC. Bopsin PS. Promoção da higienização das mãos através de técnicas lúdico-educativas em um hospital público. Caminho Aberto Rev Extensão do IFSC. 2018;5(9):77-80. doi: http://dx.doi.org/10.35700/ca.2018. ano5n9.p77-80.2443

11. Alves MM. Silveira AS, Silva JS. Sadoyama G. Impacto de programa educacional em práticas interdisciplinares na higienização das mãos (HM) por profissionais de UTI. Rev EDaPECI. 2018;18(3):61-70. doi: h区 p://dx.doi. org/10.29276/redapeci.2018.18.310107.61-70

12. Batista Neto JBS, Castro TMG, Borges RCS, Reis DLA, Medeiros TSP, Caldato MCF, et al. Construção de tecnologias educativas como forma de educação em saúde para a prevenção da Covid-19: relato de experiência. REAS [Internet]. 2020 Set [citado em: 2021 Jan 26];12(9):e3737. Disponível em: https://acervomais.com.br/index.php/saude/article/view/3737

13. Brasil. Agência Nacional de Vigilância Sanitária. Segurança do paciente: higienização das mãos [Internet]. 2017 [acesso em: 2010 Out 17]. Disponível em: https://www.anvisa.gov.br/servicosaude/manuais/paciente_hig_maos.pdf 14. Benevides JV, Pedroni VT, Carvalho ACG. Conhecendo a higienização das mãos, para uma assistência qualificada. Rev Interdiscipl Pensamento Cient. 2019;5(5):903-12. doi: http://dx.doi.org/10.20951/2446-6778/v5n5a70 